\title{
Esencia y causas en y a través de los movimientos naturales. Desde Aristóteles y en diálogo con Alicia Juarrero
}

(Essence and causes in and through the movements in Nature. From Aristotle and in dialogue with Alicia Juarrero)

\section{MIGUEL MARTÍ SÁNCHEZ}

Universidad de Navarra, Pamplona

mmarti.1@alumni.unav.es

Resumen. Según Aristóteles existe una relación intrínseca entre lenguaje ordinario, lógica y ontología, la cual es un elemento fundamental para el conocimiento de la realidad. Tal relación es aplicada por el estagirita en la esfera de la naturaleza, como apoyo para los análisis elaborados por las, en su caso incipientes, ciencias naturales. De esa manera,Aristóteles aportó una concepción unitaria de la naturaleza y de los saberes que la estudian. Sus contribuciones siguen siendo relevantes para la comprensión de la naturaleza. Mediante la confrontación de estas ideas con la propuesta contemporánea de Juarrero, con una intención de fondo semejante, se trata mostrar la actual validez de varios puntos de la reflexión aristotélica, siempre y cuando se comprendan de la manera adecuada.

Palabras clave: esencia; causas; forma; sistemas dinámicos complejos; ciencia; ontología; seres vivos. 
Abstract. According to Aristotle there is an intrinsic relation between ordinary language, logic and ontology, which is a key element for the knowledge of reality. Such a relation is applied by the Stagirite in the sphere of nature as support for the analysis made by the incipient natural sciences of his time. Thus, Aristotle provided a unitary conception of nature and the sciences which study it. His contributions are still relevant for the study of nature. This paper tries to show the present validity of the Aristotelian thought, provided it is understood in the appropriate way. This attempt is made by means of confronting Aristotle's ideas with those of a contemporary proposal, namely Juarrero's, which has nevertheless a similar intention.

Keywords: essence; causes; form; complex dynamical systems; natural sciences; ontology; living beings.

\section{Introducción}

La concepción mecanicista de la realidad natural ha recibido varios toques de atención en los últimos decenios. Matemática y ciencia físico-experimental han tenido durante años el monopolio a la hora de explicar los fenómenos naturales. Y sus contribuciones siguen siendo todavía indispensables para una visión adecuada de lo natural. Al mismo tiempo, la sucesiva y progresiva especialización de las diversas ramas de la ciencia -tanto en biología como en física- ha hecho casi imposible una visión sinóptica de esta misma realidad natural. Desde hace décadas, por ejemplo, se contrapone en el ámbito germánico la Wissenschaft a la Weltanschaaung, oponiendo una visión científica, metódica, rigurosa y objetiva, a una visión más o menos literaria, subjetiva y narrativa, que intentaría dar una visión global del mundo y los acontecimientos que lo forman, pero sin ninguna pretensión de verdad.

No obstante cabe preguntarse si realmente la ciencia experimental, en sus diversas vertientes, puede solucionar cualquier problema que se le presenta al ser humano en cuanto ser inteligente, temporal e histórico. En caso negativo no es inútil preguntarse si realmente no hay conexión alguna entre ciencia empírica y experiencia cotidiana de la realidad, tanto interna como externa, ¿son esferas irreconciliables? Como se ve esta es una cuestión ante todo metódica, es decir, de acceso o acercamiento a la realidad con el fin de dar cuenta racional de ella. ¿A qué saberes podemos 
apelar los seres humanos para hacernos cargo cognoscitivamente de las cosas que forman el mundo y los procesos que se dan en él? ¿Hay un único camino, y por lo tanto, absoluto, o bien hay una pluralidad de métodos cognoscitivos? Y si la hubiese ¿hay alguna jerarquía entre ellos? ${ }^{1}$

Me propongo exponer alguna de las ideas de Aristóteles en este punto, es decir, su opinión acerca del método o métodos de la ciencia (episteme) de la naturaleza (physis) y la relación de éstos con el conocimiento por experiencia y otros saberes, como la ontología. El estagirita no es sólo uno de los principales filósofos que han existido sino también un científico, que pensó tanto sobre el método de la ciencia (episteme) como del modo en que esta se relaciona con un saber acerca de las causas últimas (sophía o proté philosophia) y la experiencia ordinaria.

Uno de los principales problemas con los que se enfrenta un intérprete de Aristóteles es que ya la misma literatura secundaria sobre su pensamiento es abundante y muy diversificada: hay exégetas de su lógica, de su ética, de su metafísica, etc. Por lo tanto el artículo se centra ante todo en las doctrinas de Aristóteles que se consideran principales para este asunto, sin pretender, por tanto, ofrecer una síntesis acabada de su filosofía. No se tiene más pretensión que la de dar a conocer a un público poco familiarizado qué opinaba Aristóteles sobre estos temas; de un modo que permita al interesado "usarlas" en su propio intento de relacionar su actividad científica con un saber global acerca de la realidad (la cual, a mi juicio, sólo conoce de manera parcial mediante su actividad científica sea la que sea).

Como en este artículo se tratarán de explicar las razones de una posible vuelta a ciertas ideas de Aristóteles, se quiere advertir de que en alguna literatura, sobre todo científico-divulgativa, moderna y también contemporánea -en cuanto en buena medida se limita a repetir esas mismas ob-

\footnotetext{
Se da por hecho que no es cierto que el científico deba hacerse estas preguntas en cuanto científico. Pues como es obvio, aquello que constituye un problema para algunos no es necesario que sea percibido siempre así por todos, pues ni siquiera el problema es abordado mismo modo en todas las ramas del saber. No obstante, tampoco es cierto que en cuanto ser humano el científico pueda renunciar sin más a estas preguntas. Esto ocurre siempre y cuando lo que le guíe no sea simplemente no salirse de su objeto de estudio, sino aspirar a una visión completa del lugar donde se inserta su saber particular.
} 
jeciones- aparecen algunos malentendidos en torno a la física aristotélica. Desde la época de Galileo y después con Newton se ha considerado la física de Aristóteles -e incluso todas sus aportaciones a la ciencia- como completamente obsoleta, y las razones son múltiples (Arana 2002). Sin entrar en esta discusión, también conviene notar que también es cierto que, en los últimos años, se le ha considerado de nuevo como alguien con intuiciones más que interesantes para las ciencias naturales (Gilson 2009; Berti 2010; Polo 2008; Spaemann and Löw 2005). No resulta por tanto descabellado sugerir que todavía puede aportar algunas luces al campo científico, sobre todo en lo que se refiere a la biología. Siempre y cuando tales intuiciones se comprendan y usen de la manera adecuada.

De todos modos, en este texto no se va a intentar poner en el debate contemporáneo la entera filosofía natural de Aristóteles. La intención es más modesta: se quiere preguntar si, como pensaba Aristóteles, hay algún nexo entre nuestra consideración puramente científico-positiva de la naturaleza y una reflexión que hagamos de esta en cuanto cierta totalidad. O bien con otras palabras: si existe la posibilidad de acudir a otras formas de saber -además de la científica- con el fin de entender o comprender los fenómenos naturales. Concretamente interesa aplicar estas preguntas a nuestra comprensión de los seres vivos. Se da por sentado, por tanto, que la visión aristotélica de la naturaleza -aunque no exenta de prejuiciosacepta la posibilidad de que ésta fuese estudiada con métodos de diferente registro (Aristóteles 2010, 402a 17-18). Y en especial mediante el análisis que origina la ontología o metafísica como ciencia de las cosas que son en cuanto que son (Aristóteles 2012, 1003a 18-20; Berti 2010).

Para articular del mejor modo posible las preguntas aparecerá, junto a algunas de las obras más relevantes de Aristóteles en este campo, una propuesta contemporánea con la misma intención de fondo. Se trata de la obra de Alicia Juarrero expuesta especialmente en su libro Dynamics in Action (Juarrero 2002a). La propuesta de Juarrero tiene la ventaja de tener en cuenta los valiosos descubrimientos de varias ramas de la ciencia contemporánea, como la química o biología, sin dejar de acudir en varias ocasiones a alguna de las ideas aristotélicas. 


\section{Esencias y causas en la filosofía natural de Aristóteles}

Como ya se ha dicho el problema que sirve de hilo conductor es el siguiente: ¿qué relación se da entre el conocimiento cotidiano -comúnmente llamado experiencia- y aquel al que llamamos ciencia? Junto a la experiencia adquirida con el paso del tiempo, existe una actividad hasta cierto punto independiente que mediante el uso de hipótesis, lenguaje matemático y experimentos ha ofrecido un nuevo conocimiento de la naturaleza. No obstante, ese conocimiento no ha sido el primero en ser obtenido por nosotros, ni tiene por qué ser el último o definitivo, y mucho menos oponerse de manera frontal a la experiencia ordinaria del mundo. Como ha escrito Vigo:

ningún intento de abordaje de tipo causal-reductivo [como el de la ciencia contemporánea] puede dejar definitivamente atrás la dimensión originaria de la experiencia inmediata, que es la que le provee no solo su punto de partida fáctico, sino también, en definitiva, el punto de final de llegada al que apuntan, de uno u otro modo, todos sus esfuerzos explicativos. (Vigo 2011a, 275)

Como el origen del conocimiento científico es uno de los grandes temas de Aristóteles, mediante la exégesis de algunos textos se intentará mostrar cómo la elección del punto de partida es crucial para poder relacionar ambas esferas del saber, por un lado conocimiento natural o experiencia cotidiana y por otro lado conocimiento científico-experimental. A su vez el artículo se centrará en un problema todavía más concreto: ¿cabe todavía hablar, como hacía Aristóteles, de 'esencias' y 'causas' en la naturaleza con el fin de explicar científicamente el mundo natural? (Murillo 2005)2. Si como es sabido 'esencia' y 'causa' son para Aristóteles tanto conceptos

2 Las nociones de 'natural', 'naturaleza' etc., son en sí mismas algo sobre lo que se pregunta el filósofo, y en ocasiones también el científico (Schrödinger 1954), sobre todo en tanto que conceptos fundamentales. Aquí se usan de manera amplia, sin ninguna pretensión de comprensión total. Más bien en cuanto conceptos que conviene tratar con cuidado sin dar por supuesto su significado. Algo que las ciencias experimentales no tienen más remedio que hacer para llevar a cabo su objetivo. El uso principal que se le da aquí es el mismo que le dieron los primeros filósofos griegos, naturaleza en cuanto physis, es decir, en cuanto principio u origen autosuficiente, que contiene su propia regulación interna y está en constante movimiento. 
habituales del lenguaje ordinario, como lenguaje técnico-científico -hecho objeto de la ontología y aplicado en las ciencias naturales-; entonces la pregunta por la relación entre experiencia cotidiana y ciencia, va aparejada a la pregunta por las 'esencias' y las 'causas'.

'Esencia' es el término castellano que traduce el griego tò ti ên eînai, que literalmente en griego antiguo dice 'lo que era ser' (García Yebra 2012, xxx-xlviii). Se trata de una expresión que Aristóteles usa para designar lo que define o dice lo que una cosa es en sí misma. Es por consiguiente tanto un elemento de identificación como de distinción. Conviene tener en cuenta que tiene varios significados pues trata por un lado de ofrecer una definición que podríamos denominar lógica como por otro lado de mostrar un anclaje, si queremos decirlo así físico, a nuestro discurso (lógos) acerca de la naturaleza (Aristóteles 1993, 189b 30-191a 22). A mi juicio, tal es la intención de Aristóteles al usar este concepto, a saber: no desligar nunca ambos campos, ni el físico del lógico-lingüístico, ni tampoco el lógico -al hablar de los fenómenos naturales- del físico ${ }^{3}$. Así, por ejemplo, el 'era' (ên) -en imperfecto de indicativo- de la expresión tò ti ên eînai quiere mantener esa referencia constante de la definición al substrato que le precede -pues es previamente conocido- y que sigue siendo físicamente.

Antes de continuar es necesario hacer la siguiente observación: aunque se usa el término 'lógico' para la esfera no estrictamente natural, no obstante no debe entenderse por 'lógico' lo que se entiende actualmente por ello en la lógica simbólica. La lógica aristotélica es una lógica que podría denominarse onto-lógica en el sentido de que se pliega a las cosas. No es un intento de encasillar a las cosas o fenómenos en categorías abstractas -como quizá podría ser la pretensión de Kant- sino la expresión que es fruto de desentrañar la articulación y las relaciones de las cosas y seres que hay en cuanto que son (Kapp 1967). Además al añadir la palabra 'lingüístico' se tiene como objetivo señalar que esa misma lógica, en cuanto que óntica,

3 En su época tal modo de enfrentarse a la naturaleza convenía, pues las propuestas eran extremistas. O bien una física que renuncia a la lógica (Empédocles, por ejemplo), o bien una lógica que renuncia a la física (Parménides y Zenón). 
es decir plegada a la realidad, nace del lenguaje ordinario, y tiene en él su criterio de autenticidad (Vigo 2006b). De ahí la triple relación que se da según Aristóteles entre: lenguaje ordinario, lógica y ontología; la cual aplica a las ciencias naturales.

Como es sabido, para dar cuenta de la esencia juega para Aristóteles un papel importante la forma inmanente (eidos o morphé) o causa formalis de aquello que se quiere definir, separar, identificar o distinguir. Para Aristóteles no cabe hablar de substrato físico o sustancia (ousía) sin que lo consideremos al mismo tiempo como sujeto (hypokeímenon) de múltiples formas o ‘formalidades' (Aristóteles 1993, 189b 30-191a 22). Según Aristóteles la forma (eidos) inmanente a las sustancias tiene dos funciones, por un lado las organiza y regula sus movimientos, y por otro lado las hace ser lo que son. En definitiva, se trata de un principio (arché) interno e inherente a todos los seres naturales -en sentido estricto a las sustancias vivas- que se encuentran en la naturaleza. La forma no es, por tanto, una cosa (pragma), ni es a su vez identificable o visible como sí lo es el ser vivo (zoón) del cual es forma. De modo que ésta no puede descubrirse como algo que ya está ahí formando parte (en el sentido más físico o geométrico de 'parte’) del ser vivo. Más bien debe entenderse la forma como lo que de manera simultánea relaciona la realidad natural que se encuentra con movimiento incesante pero ordenado ante el sujeto cognoscente, y el conocimiento que éste tiene de esa realidad (Aristóteles 2012, 1028a 10-1041b 33). En tal relación, entre forma real y forma conocida, se juega casi toda la ciencia natural de Aristóteles. De ahí que Hegel escribiese sobre ella que:

la física aristotélica es lo que en rigor sería para los físicos de hoy la metafísica de la naturaleza, pues nuestros físicos sólo nos hablan de lo que han visto y de los finos y delicados instrumentos que han construido, pero no de lo que han pensado. (Hegel 1985, 270)

Por consiguiente si hay un hiato insalvable entre fenómenos físicos y la lógica-lingüística presente en nuestro discurso habitual elaborado a partir de la experiencia, entonces la física -y en general la ciencia natural- debe renunciar a convertirse en ciencia (episteme); en cambio, si hay alguna co- 
nexión, por mínima que sea, entonces es una ciencia posible (Boeri 2006; Aristóteles 1993, 184a 1-187a 10).

Según Aristóteles esta conexión existe porque lo que decimos de las cosas que son, da por supuesto que las cosas que son (tà ónta) ya han sido conocidas de algún modo por nosotros (Arpe 1938). Luego para garantizar este vínculo no es necesario llegar a un nuevo conocimiento, sino fundamentar -que implica cribar y aumentar- el que ya se posee (Wieland 1961, 206-219). Esta supuesta petitio principii -la naturaleza ya ha sido conocidasirve de fundamento a toda su filosofía natural. Se dice 'supuesta' porque en realidad sólo aparece como tal petición de principio -y, por tanto, como falacia argumentativa- a una subjetividad que se ha puesto en guardia frente a la realidad, y considera que es una genuina posibilidad que esa realidad se le aparezca a un sujeto como lo que no es verdaderamente.

Aristóteles y con él la filosofía antigua en general es consciente de la diferencia entre lo que parece real y lo que no lo es -véase por ejemplo el diálogo el Sofista-, pero al mismo tiempo sabe que eso sólo es posible porque lo real ya ha sido previamente conocido. Por supuesto, eso no implica que esa misma realidad no posea al mismo tiempo una cantidad de caras y dimensiones, cada una de las cuales tiene a su vez sus propias cualidades específicas; de ahí, por ejemplo, la multiplicidad de métodos necesarios para hacerse cargo de ésta: ética, lógica, dialéctica, física, filosofía primera, biología, psicología, etc. Sin embargo el conocimiento -ya sea la experiencia o la ciencia- no es nunca regla o medida de la verdad, sino las cosas las que miden el valor de nuestros conocimientos (Aristóteles 2012, 1051 b 7-8).

Junto a esto, los resultados a los que llegó la ontología en sus orígenes, y sobre todo en Aristóteles, muestran que entre eso múltiples saberes no hay una equivocidad total -y con ella separación absoluta-, porque tampoco la hay entre todas esas regiones de ser. Es posible dar con un punto en común. Piénsese en la doctrina sobre los modos de predicación -las categorías o predicamentos-, que para un filósofo griego fueron a su vez modos de aparecerse articulada la realidad en cuanto tal (Kapp 1967).

En Aristóteles esta relación entre unidad -de la realidad- y multiplicidad -tal y como ésta se presenta en el lenguaje- se conoce como la doctrina 
de las categorías, que a su vez tiene su fundamento en la semántica y pragmática plural del verbo ser (eînai) (Kahn 2003; 2009). Según esta doctrina todos esos usos y significados del verbo 'ser' se encuentran ordenados según un significado principal (focal meaning) que es el de ser en cuanto sustancia (ousía) (Owen 1960). Puede haber varias sustancias, unas pueden moverse y otras no, puede ser que a veces nos interese más cierto aspecto de la sustancia y en otras ocasiones otro, pero siempre queda un mínimo de referencia a la sustancia misma (Inciarte 1974).

De ahí, por tanto, la relación puesta de relieve más arriba entre esencia, forma y sustancia: las tres tratan de condensar la prioridad ontológica de las cosas que son propiamente y que llamamos sustancias, sobre otras cosas que, aunque secundarias con respecto a la sustancia, también llamamos seres o cosas (tà ónta), por ejemplo los accidentes que inhieren en ella. Además si se da esa prioridad ontológica entre sustancia y lo que no es sustancia, entonces lo que en sentido estricto tendrá esencia será aquella 'realidad' o 'cosa' que sea sustancial; sin que esto excluya que en cierta medida otras realidades no-sustanciales también la tengan. La esencia busca, por eso, condensar de manera rigurosa aquello en que consiste propiamente, y no por referencia a otro, una cosa o sustancia. De modo que se atiene a lo que esa cosa es, pero no prejuzga como debe ser ni la encorseta o fija. Es un concepto que podría denominarse límite.

La esencia trata, al modo de la lógica de géneros y especies o lógica de términos -descubierta y formalizada por Aristóteles-, de delimitar la definición de una sustancia, mediante la conexión de los géneros en que ésta se inscribe (Kapp 1967). A veces las categorías son llamadas géneros supremos, pues sea lo que sea algo siempre pertenece $a$, o bien se inscribe en, alguna de las categorías. Pero ésta lógica es en cierto sentido sólo extensional en cuanto que no busca dar una definición total de lo que las cosas son, sino dar un mínimo de orden por parcial y provisional que sea, entre todas esas cosas. Como decíamos, ese orden no será del todo arbitrario en cuanto que ya hay una relación intrínseca entre lenguaje, lógica y realidad. Pero tampoco será una clasificación exhaustiva, sino más bien un criterio de demarcación (piénsese por ejemplo en la definición de ser 
humano: animal que tiene razón o palabra (zoón lógon ejon) (Aristóteles 2002, 1253 a 10).

En resumen, la propuesta aristotélica, por lo que se refiere a la cuestión del método de las ciencias naturales y su relación con el conocimiento ordinario, al introducir el término 'esencia' busca dar cuenta del puente ya existente entre nuestras construcciones teóricas -en la que se encuentra cualquier tipo de ciencia, en cuanto que se hace con conceptos y proposiciones-, y las distintas realidades sobre las que hilvanamos esos discursos. Luego 'esencia' es tanto el límite o marco como el fin de la consideración científica de aquello que en cada caso es o existe. Digo límite porque es el punto de partida y digo fin porque en muchos casos la esencia ha de ser, aunque de entrada sea admitida, redescubierta. Y de ahí también la posibilidad de conectar los mundos de la ciencia contemporánea con la propuesta aristotélica.

Junto a la noción de esencia es interesante acudir a las reflexiones sobre el concepto de causa que hace Aristóteles. Según él, no hay un uso ni significado único de causa, sino que lo usamos de manera múltiple porque tiene varios significados (Aristóteles 1993, 195a 15-195b 30; Aristóteles 2012, 1013b 24-1014a 25). Ciertamente algo tienen en común pues todos ellos son la respuesta a la pregunta por el por qué algo es como es (Rossi 2005; Frede 1988). Ante la pregunta: ¿Qué hace a esta sustancia ser lo que es? Aristóteles posiblemente respondería: Depende de qué te interese saber de ella ¿su forma, su materia, el fin al que está ordenada y al que responden todos los movimientos y actividades que realiza, o bien que se trata de un móvil? Con esto Aristóteles trata de hacer notar que no siempre acudimos a la misma causa para explicar algo y, en segundo lugar, que si se opta por atender siempre a la misma causa -ya sea material, formal, eficiente o final- no por ello se entiende mejor aquello por lo que preguntamos.

Veamos el caso, por ser un paradigma de cambio en la naturaleza, de las explicaciones que Aristóteles da al describir y explicar la generación de un animal (Aristóteles 1994, 715a 1-731b 15). Sin entrar en detalles, el estagirita considera al animal superior como prototipo de sustancia (Aristóteles 2010, 415a 33-415b 10). De modo que a él, en cuanto ente natural perfecto, 
piensa el estagirita que han de poder aplicarse los cuatro tipos de causa. Como se trata de una sustancia en sentido propio no basta alguna de las causas, sino todas en su conjunto (Aristóteles 1993, 192b 8-193 b 21). Por eso puede responderse que tanto su materia como su forma, su fin y su ser un móvil le hacen ser lo que es, y si fallase alguno de ellos no podría ser ni podría llevar a cabo sus actividades más características (Aristóteles 1996, 715a-731b 15; 2010, 412b 6-7). Esta es la razón por la que Aristóteles afirma que hay varios tipos de explicación ante un mismo ser, por ejemplo, ésta física y dialéctica, dependerá de la causa a la que se privilegie en cada caso.

Antes de continuar con la generación, veamos algo más sencillo como a primera vista es el caso de la ira. ¿Qué definición de ira dará un físico y cuál dará un dialéctico? Dice Aristóteles:

Por otra parte, el físico y el dialéctico definirían de diferente manera cada una de estas afecciones, por ejemplo, qué es la ira: el uno hablaría del deseo de venganza o de algo por el estilo, mientras que el otro hablaría de la ebullición de la sangre o del elemento caliente alrededor del corazón. El uno daría cuenta de la materia mientras el otro daría cuenta de la forma específica y de la definición. Pues la definición es la forma específica de cada cosa y su existencia implica que ha de darse necesariamente en tal tipo de materia... (Aristóteles 2010, 402a 29-403b 5)

Se trata tanto de un fenómeno perfectamente identificable en la realidad natural -actualmente se hablaría ahora del cerebro-, y al mismo tiempo se le asocia con ciertos efectos o fenómenos asociados que permiten identificarlo cuando se produce a cualquier sujeto sin necesidad de poseer un conocimiento científico. Según Aristóteles ambas explicaciones son compatibles. Una ha acudido a la causalidad material y en cierto sentido a la eficiencia, en cambio, la segunda se fija ante todo en la forma y el fin.

Por supuesto para el estagirita no se trata de preferir unas causas a otras, como si sólo importase alguna o algunas. A su juicio, todas las causas juegan un papel determinado e insustituible, y caer en la cuenta de eso forma parte del núcleo de esta doctrina. El problema se produce por tanto, al renunciar a alguna de ellas sin necesidad de hacerlo, o bien pretender 
agotar todas las explicaciones causales acudiendo sólo a una o dos de las causas.

Según la reconstrucción histórica que hace Aristóteles de sus predecesores (Aristóteles 2012, 983b-993a 22), éstos descubrieron principalmente las explicaciones que acudían a la causa material. Sin embargo, con ello no agotaban las posibilidades de una explicación científica. El nuevo modo de preguntar de Sócrates, y después de Platón en sus múltiples y brillantes Diálogos -por ejemplo en el Fedón- abrió la puerta a explicaciones de tipo formal e incluso teleológico. De modo que la tarea de Aristóteles consistió sobre todo en unir y relacionar ambos modos de referirse causalmente a la naturaleza. Aquí encaja, por ejemplo, la diferente función que juega la materia en las explicaciones científicas si se admite también o no la causalidad de la forma y del fin. Porque en el caso de aceptar esa causalidad formal y final, la materia aunque necesaria, lo es sólo como condición sin la cual -o necesidad ex hypotesi- no pueden producirse a su vez los movimientos y actividades correspondientes a un ser natural (Aristóteles 1993, 199b 35-200b 7).

Volvamos a la generación del animal. Aquellos seres en los que materia, forma, movimiento y fin no pueden separarse sin perder la unidad que les es característica los llama Aristóteles naturalezas (physei) -entre las que destacan los animales por ser los que mejor cumplen ese requisito-. Les caracteriza que tienen en sí mismas el principio del movimiento y del reposo (Aristóteles 1993, 192b 20-25). Por eso son en cierto sentido principio y según esto autosuficientes. No bastará por tanto una explicación que proceda por partes y divisiones si se quiere captar de manera genuina en qué consiste su esencia. Por consiguiente son necesarias para una explicación genuina todas las causas.

Conviene destacar que para Aristóteles uno de los puntos a tener en cuenta es que ese movimiento que les es esencial a los animales -y a las sustancias vivas en general- no las exime de poseer una esencia, es decir, algo que permita identificarlas a lo largo del tiempo y de los sucesivos cambios. Ser naturaleza (physis) es por tanto ser sustancia de un modo determinado, a saber: aquel según el cual la forma y el fin se acoplan con 
las otras dos formas de causalidad sin eliminarlas. Por eso, paradójicamente, aunque en algunas explicaciones científicas contemporáneas se suele asociar el movimiento, el cambio y la transformación a la causa material, en el sentido de que esta es corruptible y modificable, para Aristóteles aquello que propiamente se mueve es aquello en lo cual la causa formal, por decirlo así, sobresale; siendo la forma -y en cierto sentido también el fin- la que mueve, organiza y regula el movimiento. La forma no libera de la necesidad de los movimientos y los cambios, sino que los mantiene unidos y organizados.

Según Aristóteles, en los seres vivos -sobre todo en los animales más desarrollados- la unidad y la identidad adquieren significado propio; es decir, se es uno al modo de una sustancia viva. Y sin embargo, los cuatro sentidos causales, y no sólo la forma o el fin, son necesarios para dar cuenta de ellos de manera científica -recuérdese lo que se decía de la causa material como necesidad hipotética-. Por ejemplo, la nutrición en cuanto actividad sólo puede serlo en cuanto ejecutada por un ser vivo, el cual no simplemente se alimenta en cuanto que es material, sino también en cuanto principio motor, forma y fin. Todas estas causas funcionan como explicación en un determinado nivel. Véase el siguiente ejemplo, ¿el alimento es alimento siempre o sólo lo es en cuanto que hay algo que se alimenta con él? Con otras palabras, ¿fuera de un ser capaz de asimilar lo externo a él y al mismo tiempo transformarlo en parte de sí mismo sin perder su unidad, existe algo así como 'alimento'? (Aristóteles 2010, 416a 19-416b 33).

Del mismo modo, puede hacerse una analogía entre lo que ocurre con el alimento y lo que sucede con otros muchos movimientos del ser vivo. Lo común a todos ellos es que aquel ser que se mueve y transforma no pierde la unidad -dejemos de lado la corrupción- a pesar de recibir influjos externos, sino que asume esos cambios -siempre que éstos no sean mortalespara continuar siendo uno. De modo que en estos seres el movimiento no es algo superpuesto a su unidad, sino lo propio y sin lo cual no sería uno de ninguna manera. Por eso, para Aristóteles, un ser vivo es aquel que es uno en y a través del movimiento, o en sus palabras "el vivir para los vivientes es ser" o "la vida se da en el movimiento" (Aristóteles 2010, 415b 13). 
Hasta aquí la exposición de las tesis aristotélicas. Se ha mostrado que las nociones de esencia y causalidad son para Aristóteles tanto una muestra del anclaje del discurso racional en una realidad que es lo que es de manera independiente o separada (hóriston), como garantes de una explicación científica de la naturaleza. Y que éstos conceptos no llevan aparejado de ninguna manera un cierto 'fijismo' incapaz de asumir el movimiento como algo esencial a la naturaleza en general y a las sustancias vivas en particular. Más bien al contrario, con sus herramientas conceptuales y el recurso a otros saberes -ontología, análisis lingüístico, observación empírica y análisis de esa misma experiencia ordinaria- es posible dar cuenta racional de este factor -la naturaleza es móvil-, sin perder el rigor al que obligan las explicaciones lógico-racionales.

\section{Diálogo crítico con Alicia Juarrero}

En el libro Dynamics in Action (Juarrero 2002a) Alicia Juarrero intenta poner de relieve esta conexión entre unidad y movimiento, y en definitiva trata de formular una explicación sintética y unitaria de la naturaleza y sus fenómenos. Pero al intentar hacerlo se ve obligada a usar conceptos con los que la ciencia contemporánea no contaba o había descartado. Desde el momento en que la ciencia, por razones de método, renuncia a la totalidad y se fragmenta en múltiples saberes, pierde la capacidad de unir los trazos dispersos. Con esa parcialización también los conceptos sufren mutaciones de diferente tipo, por lo que una comprensión unitaria no tiene más remedio que cuestionarlos en cuanto tales. De modo que su propuesta se enmarca dentro de un proyecto ambicioso: dotar de un nuevo método explicativo a las ciencias experimentales, sobre todo en lo que se refiere a sus explicaciones acerca de los seres vivos y de las acciones humanas. Contiene, por ello, muchas críticas al método nomológico-deductivo, es decir, al procedimiento racional que tiene como práctica habitual deducir de leyes los comportamientos y otros efectos. En este sentido, apuesta por ampliar las nociones de causa y explicación tal y como son usadas por la ciencia empírica contemporánea. 
Como veremos, Juarrero reconoce en varias ocasiones su cercanía con algunas de las tesis de filosofía natural más conocidas de Aristóteles, como son por ejemplo su introducción de la teleología o el papel que concede a una cierta causalidad formal en los fenómenos naturales. Esto no significa que no muestre sus discrepancias; por ejemplo, piensa que la teoría aristotélica no sería capaz de dar cuenta de la evolución y tampoco en lo que se refiere a una cierta auto-causalidad (self-causation) que se da durante el desarrollo de los seres vivos.

La confrontación de ambas posturas tendrá tres partes: la primera 1) será una exposición de la propuesta más relevante de Juarrero con el fin de compararla con la aristotélica, a saber: los sistemas dinámicos complejos (se usará también el acrónimo SDC); en segundo lugar, 2) explicar las líneas de contacto con la exposición aristotélica; y por último 3) abordar dos problemas inherentes a la propuestas tanto de Aristóteles como de Juarrero para averiguar la viabilidad de ambos planteamientos: explicar la posibilidad de la identidad a través de los cambios; y la vigencia del principio de no-contradicción también para la esfera de la naturaleza.

\subsection{Propuestas en Dynamics in Action}

Como decíamos, la propuesta de Alicia Juarrero contiene tanto una introducción de nuevos tipos de causalidad no aceptados como científicos por buena parte de la ciencia actual, como otro modo de explicar los acontecimientos naturales distinto al que se encuentra en boga en esta ciencia. No obstante, también rechaza un planteamiento filosófico que sea incapaz de incorporar los nuevos datos proporcionados por la ciencia actual, por ejemplo en terrenos como la biología molecular, la física cuántica o la genética ${ }^{4}$.

Según ella, hay determinados fenómenos naturales -por ejemplo, las acciones humanas- que a pesar de ser algo observable en el sentido de empírico no pueden ser explicados adecuadamente mediante el método

4 Esto último es especialmente importante, como veremos, para entender sus objeciones a la metafísica clásica, en especial como normalmente se entiende desde el paradigma griego de Platón y Aristóteles. 
legal-deductivo adoptado por las actuales ciencias de la naturaleza. Por ello es necesario introducir tanto un nuevo modo de causalidad como de explicación científica. En su opinión estas dos ideas se condensan en su propuesta de los sistemas dinámicos complejos. Según sus propias palabras:

A central claim of this book is that the conceptual framework of the theory of self-organizing dynamical systems has significant implications for the philosophical concepts of identity, teleology, cause, and explanation. In combination with the concepts of noise and equivocation borrowed from information theory, a "theory-constitutive-metaphor" taken from the science of complex adaptive systems can renew the study of action opening up novel questions and avenues for explanation. (Juarrero 2002a, 123)

En su opinión, se debe poner de relieve que para comprender y explicar los principales fenómenos que observamos en la naturaleza -como puede ser el origen y desarrollo de un ser vivo- no se puede prescindir del contexto, de la individualidad y de la finalidad. Esto es necesario, sobre todo, si queremos comprender a los seres vivos y al que parece más complejo de todos ellos: el ser humano.

Según explica Juarrero, causar no es solo producir efectos predeterminados y reglados por una ley y, por tanto, predecibles y lineales; sobre todo porque desde esa perspectiva lo único que sería relevante para explicar un fenómeno serían sus condiciones iniciales. Sin embargo, como es sabido, en muchos fenómenos -como las Bénard Cells- no basta con acudir a esa noción de causalidad. Principalmente, porque un uso tan restrictivo del concepto de causa impide dar cabida en la naturaleza a la producción de novedades emergentes, finalidad y auto-organización. E incluso, en último término, hace imposible un discurso coherente acerca de la libertad en seres naturales como el ser humano. Por el contrario opina ella que:

complex adaptive systems exhibit true self-cause: parts interact to produce novel, emergent wholes; in turn, these distributed wholes as wholes regulate and constrain the parts that make up them... (Juarrero 2002a, 130) 
Para resolver este punto, la principal aportación de Juarrero es su teoría de que hay elementos o seres de la naturaleza que se organizan a sí mismos, los ya nombrados sistemas dinámicos complejos. El problema está en cómo dar cuenta de ellos de manera científica y no sólo metafórica. La idea fundamental es que hay seres en la naturaleza que se desarrollan y regulan a lo largo de su vida desde sí mismos. Entre otras razones, porque los sucesivos niveles que van apareciendo en el desarrollo vital de ese sistema organizan al nivel inferior para hacerle capaz no sólo de dar lugar al superior sino también de sostenerlo. Aquí aparece la ampliación del concepto de causa: la atracción de unas partes entre otras y de unos niveles entre otros no se capta realmente a partir de una causalidad sólo eficiente, predecible y lineal; es necesaria una causalidad formal y final. Así, en el caso de la acción humana no puede decirse -si se acepta el presupuesto que toda acción humana es por definición libre- que reside en las partes o condiciones iniciales, sino que surge a partir del propio sistema, pero sin hacerlo de manera necesaria o predeterminada.

El correlato epistemológico de la ampliación del concepto de causa implica la aportación de un método menos restrictivo que el nomológico-deductivo. La afirmación de que: los seres que propiamente se dice que son-los SDC en este planteamiento- se forman y mantienen siempre como individuos en un entorno que les es esencial porque los configura, trae consigo aparejada la necesidad de un método que incluya estos factores como algo relevante para la explicación. A su juicio, el modo de afrontar los problemas de la acción libre y de la auto-organización de los seres vivos desde la ciencia experimental y el método nomológico-deductivo los deja intactos, o, peor aún, intenta eliminarlos por reducción a otros fenómenos menos complejos. Según Juarrero ese problema se podría solucionar mediante el uso de una hermenéutica de la naturaleza para la que se remite a la obra de H. G. Gadamer: Wahrheit und Methode.

En resumen, según las descripciones de Dynamics in Action, los SDC son aquellos seres que, si bien son unidades, no puede hablarse de ellos como de principios fijos. Forma parte esencial de su modo de ser el estar en constante movimiento, porque sin ese movimiento no serían lo que 
son. Por eso mismo, para los SDC estar insertos en un medio no es algo accidental, sino que en la relación con el medio que les rodea llegan a ser lo que son. Como dice Juarrero:

The central lesson of complex adaptive systems is that when everything is ultimately connected to everything else, expecting to isolate one aspect of a problem and dealing with it, solve the entire problem is a senseless endeavor. Taking the web metaphor seriously means that just as movements on one end of trampoline affect the other end, modifications to one portion of a probability landscape automatically alter the rest: a particular contextual setting that increases the probability of $\mathrm{x}$ on this end of the net will automatically alter the probability of $y$ on the other, often unpredictably. A different time or place might not alter the probability that $\mathrm{x}$ will happen, yet another time or place might even lower it. That is what taking dynamics and context-dependence seriously is all about. (Juarrero 2002a, 249)

\subsection{Líneas de contacto con la exposición aristotélica}

Según Juarrero estas dificultades implican la necesidad de apelar a nuevos conceptos o ampliar los ya conocidos. Entre estos términos, algunos ya fueron planteados por pensadores como Aristóteles, como el concepto de esencia, causa formal, causa final, enérgeia, entelecheia y dynamis. Puede decirse que ambos -Aristóteles y Juarrero- coinciden ante todo en dos puntos:

El primer punto en común es la ampliación de significados del concepto de causalidad. Tanto para el uno como para el otro, las dificultades se multiplican si se pretende que sea una sola causa la que dé cuenta de todos los fenómenos que se producen en la naturaleza. En segundo lugar, la concepción de fondo según la cual los seres naturales deben cambiar, es decir permanecer en movimiento, para seguir siendo lo que son. Por lo tanto, para descubrir la identidad de un ser natural, no basta con enunciar una serie de propiedades insustituibles y que no cambien. Más bien es necesario admitir que su misma identidad exige la continua modificación de las partes y el todo, y que hay que descubrir en ese mismo desarrollo el hilo conductor que hace posible su identidad. 
En concreto, para Juarrero ese hilo conductor no es otra cosa que las relaciones que ese mismo sistema es y establece entre las propias partes del sistema dinámico complejo y las que se dan entre en el sistema y el entorno en el que está inserto (Juarrero 2002b, 99).

También Aristóteles era consciente de la dificultad para dar cuenta racional de la naturaleza en cuanto sede del cambio y la multiplicidad: ¿permanece o no permanece algo en el cambio? Por eso se apoyó en conceptos tales como el de causa -con sus múltiples significados- y esencia, y creyó encontrar en ellos un puente de unión fiable para ir y venir desde el ámbito del lógos al de la physis. Por otro lado, como decíamos, Juarrero tiene la misma intención de fondo, según ella esa apertura metodológica se ha perdido en las explicaciones de la ciencia natural contemporánea, por eso acude a las nociones de causalidad formal y final y a los SDC.

Ahora bien esto no significa que haya un acuerdo total entre la física y metafísica de Aristóteles y la filosofía natural de Juarrero. La objeción principal de Juarrero a Aristóteles es que con el fin de racionalizar la naturaleza acabó por ceder a la tentación de trasladar esquemas lógicos a los fenómenos naturales. En concreto le achaca que:

a) Aunque Aristóteles fue consciente de este inconveniente, no llegó a proponer la noción de self-causation, sino que más bien la descartó.

b) A juicio de Aristóteles, la relación que establecen los seres con esencia con aquello que no son esencias no constituye lo que estos son. En cambio estas relaciones son fundamentales para un SDC.

c) En definitiva, Aristóteles es todavía dependiente de una concepción 'fijista' de la realidad, es decir, incapaz de explicar el surgimiento de algo no previsto en la naturaleza. Porque las esencias son para él siempre las mismas.

\subsection{Aristóteles y Juarrero sobre la posibilidad de la identidad a través de los cambios y el Principio de no-contradicción}

El siguiente apartado es un intento de mostrar que en Aristóteles tal incompatibilidad entre el ámbito físico o natural y el lógico no existe, al 
menos como es enunciada por Juarrero. Sí hay, por pura diferencia radical entre el pensamiento humano y la realidad, distinción entre ambas esferas. Más bien fue Aristóteles el que, gracias al equilibrio entre lógica y naturaleza, consiguió dar cuerpo científico tanto a la física como a la metafísica. Queda por ver que tal cosa sea posible si, como parece sugerir Juarrero con los SDC, basta con quedarse en una cierta hermenéutica de la naturaleza.

Para el uso del lenguaje ordinario que hace posible nuestro constante darnos a entender, y que presupone (al menos prima facie) el acceso a lo real -a la esencia de las cosas-; es necesaria la limitación o delimitación del significado (Vigo 2011b). De otro modo, no habría referencia, significado ni sentido, según la famosa distinción elaborada por Gottlob Frege (Frege 1892). Al mismo tiempo, la misma diferencia entre sujeto y predicado, que presupone una estructuración del mundo no-arbitraria, carecería de sentido. Por último, como decíamos, el hecho cotidiano de una predicación recta (sintaxis) y correcta (verdadera) supone que nos hacemos cargo de la "esencia" de las cosas -no en sus últimas notas-, sino en cuanto a lo diferencial o definitorio: su lógos (Vigo 2011b).

Tal conocimiento es normalmente el punto de partida de cualquier razonamiento posterior. Para poder avanzar en un conocimiento no auto-refutativo, es necesario que los juicios primeros sean verdaderos. De otro modo, el discurso elaborado no posee un criterio desde el que evaluar su correspondencia con lo real, y desde el cual distinguir entre el discurso sobre las cosas elaborado, por ejemplo, por un niño y el de alguien que conoce científicamente lo real.

Es fácil advertir que como se decía más arriba, la causa formal juega en este caso, por lo menos, un doble papel en el pensamiento del estagirita. Por un lado, permite la identificación de los objetos, y a partir de esta identificación elaborar la definición. En segundo lugar, esto es posible porque la causa formal (eidos-morphé) es:

el principio que regula y orienta [el] [...] proceso de generación y crecimiento, [por eso] puede decirse que, en el caso de cosas naturales, como los seres vivos, la materia misma está sujeta al poder configurador de la forma: es, pues, 
la forma, como principio configurador activo, lo que garantiza la unidad y la persistencia del compuesto orgánico, con su peculiar constitución material y la correspondiente diferenciación de sus partes... (Vigo 2010, 590)

No obstante, la causa formal no aísla al ser vivo del entorno en el que está inserto -una de las objeciones que hacía Juarrero a Aristóteles, en concreto la b)-, pues como continúa Vigo:

la conexión estructural que vincula el fenómeno del movimiento con la composición hilemórfica puede explicarse con arreglo a, por lo menos, tres aspectos fundamentales [...] El hecho de que el objeto natural sea un compuesto de materia y forma [hay un sujeto que no está sometido a cambio en el mismo sentido en el que está sometida la materia] implica que no hay identidad estricta entre el objeto y su forma específica [...]. La propia composición implica que, en muchos casos, las propiedades formales específicas del objeto compuesto no estén dadas todas de modo efectivo desde el comienzo, sino que se presenten de ese modo recién al cabo de un proceso natural de desarrollo, presidido por la función reguladora y configuradora de la forma, la cual se realiza plenamente como tal solo al termino de dicho proceso. (Vigo 2010, 591)

Por lo tanto, que la forma sea causa activa, y al mismo tiempo sea origen de la identificación de la sustancia compuesta, no es incompatible con que las relaciones que establezca con el entorno sean también dinámicas.

Aunque sin ánimo de entrar en las discusiones, conviene señalar que existen varias paradojas que surgen de esta dualidad de la causa formal. Una es la llamada paradoja de la unidad (paradox of unity): si un ser vivo está en constante movimiento, ¿cómo puede hablarse de ese ser vivo y predicar sobre él como si fuese algo si decimos que en cuanto ser vivo está en constante cambio? (Gill 1989, 6). Además, como segunda paradoja, podría añadirse que, según Aristóteles, sólo aquellas realidades que no dependen de otras para ser definidas pueden figurar al mismo tiempo como sujeto de predicación y como un ser en sí mismos (kath'autó) o sustancia (ousía).

También esta objeción se aplica a la propuesta de los SDC de Alicia Juarrero. Pues si los SDC no tienen límites porque un límite implica estabilidad, porque lo que un SDC es depende solo de la dinámica interna del 
propio sistema y de las conexiones que establece con su entorno, entonces qué es. La total ausencia de límites, si se entiende como una continua actividad que impide identificar tal sistema, haría también imposible un juicio verdadero sobre el sistema en cuanto tal. Sin embargo Juarrero afirma que:

Because a CDS is open to its environment, sharp boundaries between the system and its environment are difficult, if not impossible, to draw; a CDS's external relations are as critical to it as its internal ones; a CDS's environment and history are as critical to it as its intrinsic attributes; because a CDS adapts and evolves, the concept of essence as a nucleus of intrinsic and immutable qualities cannot handle a CDS's dynamical characteristic, particularly its embeddedness in time and space. (Juarrero 2002b, 97)

Ahora bien, si los SDC aspiran a concentrar en su interior fenómenos que de suyo no forman algo unitario, y de este modo poder generar realidades hasta ese momento inéditas -no determinadas por las condiciones iniciales-, deberían ser capaces al mismo tiempo de ser definidos sin apelar a componentes que les precedan en cuanto a lo que son. Lo que tiene como consecuencia que la definición se hace imposible pues no hay algo previo y determinado, por mínimo que sea.

No obstante si los SDC pretenden aspirar a jugar un papel semejante al que la sustancia material y compuesta tiene en la ciencia natural aristotélica -cosa que Juarrero parece sugerir al apoyarse en la noción de causa formal-, el sujeto real de los cambios no puede ser algo indeterminado. Porque todo lo que es, en cuanto que es, tiene podría decirse, junto a su materialidad, una estructura interna o forma (eidos) que le hace ser lo que es, y que permite la conexión - palmaria al menos en un nivel de experiencia ordinaria- entre nuestro modo de predicar o hablar sobre las cosas, y el modo en el que estas están configuradas físicamente y continúan desarrollándose.

En el caso de que esto no se acepte: i) ¿de qué hablaríamos cuando hablamos de un SDC?, y ii) ¿cómo diferenciar entonces un SDC de otro?

Por otro lado, según Aristóteles, para sostener la existencia, en concreto, de sistemas autosuficientes no es suficiente apelar a que son individuales y tienen una dinámica interna propia -lo que él llamaría ser un ti esti 
y horistón-, sino que es necesario que también pueda hacerse sobre ellos cualquier predicación -accidental o esencial-, pero que ellos mismos no puedan ser predicados de otra cosa. De otro modo, el individuo no tendría consistencia -no sería más que un agregado- o bien sería incognoscible. Juarrero propone, a mi juicio de manera ad hoc, el uso del término 'invariance', que define como:

which purports to identify a dynamical set of relations that remain the same despite undergoing certain transformation. The difference between the concept of invariance and the traditional concept of identity is not only in the concept of invariance's focus on relations, but in particular in its inclusion of external as well as internal relations, which are conceptualized as dynamic, not merely static, links... (Juarrero 2002b, 99)

\section{Conclusiones}

Lo cierto es que, como recuerda Aristóteles, cuando hablamos, hablamos de algo, ya sea natural o artificial, apelamos a conceptos -en este caso ya vertidos además en palabras- como animal, hombre, máquina; y sólo después de esto - del uso de conceptos con referencia y significado previos- podemos llegar a dudar o, al menos, cuestionar si la diferencia entre uno y otro concepto es tan clara como la que se marca en el uso cotidiano del lenguaje. Sólo si son diferentes podemos decir que el uno no es el otro, y viceversa. O bien, que uno llega a ser el otro (el que antes no era). Pero si no podemos decir lo que era antes (tò ti en eînai), tampoco podríamos explicar cuál es el cambio que ha sufrido, y ni siquiera el tipo de cambio que ha sufrido; a saber, o bien sustancial, o bien accidental. En resumen pueden señalarse las siguientes objeciones a la propuesta de Alicia Juarrero:

1. ¿Cómo sería posible a partir de una concepción de movimiento continuo y, en principio, no distinguible en primario y secundario, un discurso verdadero sobre esos mismos sistemas dinámicos complejos?

2. ¿Cómo se conjugaría tal modo de ser de los SDC con el modo de referirnos a ellos como si fuesen algo más o menos estable? ¿No hay ninguna correspondencia? Si la hay, ¿de qué tipo? 
3. ¿Qué significaría entonces cambiar para un SDC? ¿Puede hablarse realmente de un cambio cuando no hay identidad previa y un opuesto -posible por la identidad- hacia el que se cambia?

\section{Referencias}

Arana, Juan. 2002. Universo. Materia. Vida. Madrid: Tecnos.

Aristóteles. 1993. Física I-II. Translated by Marcelo D. Boeri. Buenos Aires: Biblos. Aristóteles. 1994. Reproducción de los animales. Translated by Ester Sánchez. Madrid: Gredos.

Aristóteles. 2010. Acerca del alma. Translated by Marcelo D. Boeri. Buenos Aires: Biblos.

Aristóteles. 2012. Metafísica. Translated by Valentín García Yebra. Madrid: Gredos.

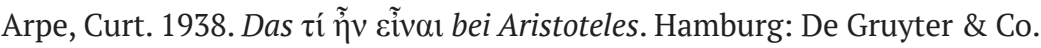

Berti, Enrico. 2010. Struttura e significato della Metafisica de Aristotele. Roma: EPUSC.

Boeri, Marcelo D. 2006. "Aristóteles contra Parménides: el problema del cambio y la posibilidad de la ciencia física.” Tópicos. Revista de Filosofía 31:45-68.

Frege, Gottlob. 1892. „Über Sinn und Bedeutung.“ Zeitschrift für Philosophie und philosophische Kritik, NF 100: 25-50.

García Yebra, Valentín. 2012. Introducción a Metafísica de Aristóteles: edición trilingüe. Madrid: Gredos.

Gilson, Étienne. 2009. From Aristotle to Darwin and back again: A journey in final causality, species and evolution. San Francisco: Ignatius Press.

Gill, Marie L. 1989. Aristotle on Substance. The paradox of unity. New Jersey: Princeton University Press.

Hegel, Georg W. F. 1985. Lecciones sobre la historia de la filosofía. Translated by Wenceslao Roces. México: Fondo de Cultura Económica.

Inciarte, Fernando. 1974. El reto del positivismo lógico. Madrid: Rialp.

Juarrero, Alicia. 2002a. Dynamics in action: intentional behavior as a complex system. Massachusetts: MIT Press.

Juarrero, Alicia. 2002b. "Complex Dynamical Systems and the Problem of Identity." Emergence 4 (1/2): 94-104.

Kahn, Charles H. 2003. The Verb 'Be' in Ancient Greek. Dordrecht: Hackett Publishing Company, Inc.

Kahn, Charles H. 2009. “The Greek verb 'to be' and the concept of being." In Essays on Being, edited by Charles H. Kahn, 17-40. Oxford: Oxford University Press. 
Kapp, Ernst. 1967. Greek Foundations of Traditional Logic. New York: Columbia University Press.

Katayama, Errol G. 1999. Aristotle on artifacts: a metaphysical puzzle. Albany: State University of New York Press.

Murillo, José I. 2005. “El nacimiento de la antropología en Grecia: Polo y la concepción de Platón sobre el hombre.” Studia Poliana 7:7-23.

Owen, G.E.L. 1960. "Logic and Metaphysics in Some Earlier Works of Aristotle," In Plato and Aristotle in the Mid-Fourth Century, edited by I. During, and G.E.L. Owen, 163-190, Göteborg: Almquist and Wiksell.

Polo, Leonardo. 2008. Introducción a la filosofía. Pamplona: Eunsa.

Rossi, Gabriela. 2011. El azar según Aristóteles. Estructuras de la causalidad accidental en los procesos naturales y en la acción. Bonn: Akademia Verlag.

Schrödinger, Erwin. 1954. Nature and the Greeks. Cambridge: Cambridge University Press.

Spaemann, Robert, and Reinhard Löw. 2005. Natürliche Ziele. Geschichte und Wiederentdeckung des teleologischen Denkens. München: Klett-Cotta.

Vigo, Alejandro G. 2006. Aristóteles. Una introducción. Santiago de Chile: IES.

Vigo, Alejandro G. 2010. “Explicación causal y holismo de trasfondo en la filosofía natural de Aristóteles.” Kriterion 122: 587-615.

Vigo, Alejandro G. 2011a. Estudios aristotélicos. Pamplona: Eunsa.

Vigo, Alejandro G. 2011b. "Naturalismo transcendental.” In Aristotle: Metaphysics and practical philosophy: Essays in honour of Enrico Berti, edited by Enrico Berti, and Carlo Natali, 111-142. Louvain-la-Neuve: Peeters.

Wieland, Wolfgang. 1961. „Das Problem der Prinzipienforschung und die aristotelische Physik.“ Kant Studien 52, 1-4: 206-219.

Wieland, Wolfgang. 1970. Die aristotelische Physik: Untersuchungen über die Grundlegung der Naturwissenschaft und die sprachlichen Bedingungen der Prinzipienforschung bei Aristoteles. Göttingen: Vandenhoeck \& Ruprecht. 